\title{
Utilizing associational resistance for biocontrol: impacted by temperature, supported by indirect defence
}

Sari J Himanen ${ }^{1 *}$, Thuy Nga T Bui ${ }^{2}$, Mengistu M Maja² and Jarmo K Holopainen²

\begin{abstract}
Background: Associational herbivore resistance is potentiated by neighbouring heterogenic plant species that impact a focal plant's attraction to herbivores or the damage that they cause. One mechanism to confer associational resistance is believed to be exposure to neighbour-emitted volatiles, the receivers of which range from intra- and interspecific neighbour plants to higher-trophic-level insects. In previous studies the passive adsorption of neighbouremitted semivolatiles has been reported, but little is known regarding the mechanisms and ecological consequences on the receiver plant and its associated biota. To utilize volatile-based associational resistance for agricultural applications, it is imperative to know its effectiveness under varying diurnal temperatures and whether herbivore natural enemies, providing biological control, are impacted. Mimicking varying diurnal temperatures in a laboratory set-up, we assessed how the tritrophic model system Brassica oleracea var. italica (broccoli)-Plutella xylostella (crucifer specialist herbivore)-Cotesia vestalis (endoparasitoid of P.xylostella) is influenced by exposure to the natural semivolatile emitter plant Rhododendron tomentosum Harmaja.

Results: Rhododendron tomentosum-exposed B. oleracea was less susceptible to P.xylostella oviposition at both night-time $\left(12^{\circ} \mathrm{C}\right)$ and day-time $\left(22^{\circ} \mathrm{C}\right)$ temperatures and less favoured and damaged by P.xylostella larvae at $12^{\circ} \mathrm{C}$. Exposure did not interfere with indirect defence, i.e. attraction of the natural enemy $C$. vestalis on host-damaged, $R$. tomentosum-exposed $B$. oleracea under $22^{\circ} \mathrm{C}$, while there was a reduction in attraction (marginal preference towards host-damaged B. oleracea) under $12^{\circ} \mathrm{C}$.

Conclusions: The ability of $R$. tomentosum exposure to render associational resistance against an agriculturally important Brassica herbivore P.xylostella without severely compromising the specialist parasitoid C. vestalis host location encourages further studies on the potential of using this naturally abundant plant for biocontrol. The generality of our finding on temperature as a potential regulating mechanism for the efficacy of semivolatile emitter-based associational resistance towards specialist pest larval damage should be further studied in natural and agricultural associations. Our study emphasizes the need to develop techniques to compare volatiles at the leaf versus air interface and associate their appearance and ecological role with times of activity and level of specialisation of herbivores and their natural enemies.
\end{abstract}

Keywords: Associational resistance, Herbivory, Host location, Indirect defence, Parasitoids, Semivolatiles, Temperature

\section{Background}

Associational resistance, the protection of a focal plant from herbivory via neighbouring a heterogenic species $[1,2]$, is an example of how plant-plant interactions

\footnotetext{
*Correspondence: sari.himanen@luke.fi

${ }^{1}$ Natural Resources Institute Finland (Luke), Management and Production of Renewable Resources, Production Systems, Lönnrotinkatu 5,

Fl-50100 Mikkeli, Finland

Full list of author information is available at the end of the article
}

might affect plant defence against biotic attackers. Such neighbour-mediated resistance is believed to operate via multiple strategies: the "resource concentration hypothesis" is based on lower host plant density and reduced accessibility to host plants by attacking herbivores in mixed communities [3], and the "enemies hypothesis" predicts that natural enemy abundance is increased when food sources and shelter are provided by neighbours, thereby reducing herbivory [4]. The 
"semiochemical diversity hypothesis" relies on volatiles disturbing herbivore olfaction, which is used in host location and reproduction [1]. Airborne plant volatiles are important infochemical cues for associated specialist species biota in particular [5]. The host location by insects [6] and the activation of a plant's inducible defences to attract natural enemies of herbivore attackers [7] to provide indirect defence are partly regulated by volatile signals. The complexity of volatile signalling in multitrophic systems is illustrated by numerous recent findings suggesting novel mechanisms for volatile-mediated interactions. Such examples include the passive adsorption and re-release of neighbours' defensive volatiles with semivolatile characteristics, i.e. low vaporization rate to the gaseous phase, on the surface of interspecific foliage [8].

Associational resistance as mediated by plant volatiles has recently been demonstrated for a number of associations [8-11]. Associational resistance in general has been utilised for decades in agriculture in the form of mixed cropping with the aim of reducing pest damage $[12,13]$. Only in approximately $50 \%$ of cases, has pest protection by neighbours been effective in mixed cultures [14]. Specific aromatic plant volatiles have often been tested with success for the purpose of repelling or masking host cues (i.e., olfactory camouflage) towards herbivores in various types of agroecosystems (e.g., $[15,16])$, although the active role of the chemical component has also been doubted, and opinions have been raised in favour of companion crops acting as pure physical barriers [17]. Variation in the environmental conditions and specificity by the studied plant-herbivore system can complicate revealing any general underlying mechanisms providing associational resistance alone or in concert with other simultaneously acting interactions [9]. Much remains to be revealed regarding multitrophic interactions that are mediated by volatiles, particularly on their environmental persistence [18-21], potential trade-offs between the many ecological effects to which they contribute [22], and their co-evolution and adaptive value [23]. The utilization of associational resistance for biocontrol in the form of trap crops $[24,25]$, repellent or host odour-masking companion plants [16], intercropping [15], or synthetic compounds released from dispensers [26] might also benefit greatly from an improved understanding of the mechanisms regulating volatile-mediated associational resistance.

Understanding the concurrent roles and interplay between different volatile-mediated interactions (with the same compound changes potentially impacting multiple interactions simultaneously) is essential when aiming to utilize volatiles in pest protection. For example, a trade-off might exist if the adsorbed compounds, which are emitted by the neighbour and confer associational resistance, interfere with the attraction of natural enemies to suppress herbivore pressure [22]. Thus, when designing biocontrol applications based on volatiles, impacts on both the herbivores [16] and their natural enemies [27-29] and, optimally, the persistence of impacts under abiotic variation as encountered in field environments should be considered. Neighbour volatiles might variably impact natural enemies, as recently shown for ladybirds on potato exposed to onion volatiles: TMTT was an attractant, whereas $(E)$-nerolidol acted as a repellent [30]. If the neighbour-emitted compounds are semivolatile in nature, the impact might be even stronger or more prolonged.

The stability and functional distance of associational resistance is another puzzling issue also when considering airborne plant volatiles in field conditions [21, 31]. Because insect olfaction is believed to be remarkably sensitive [6], small changes in volatile signals may reveal or disguise a great deal of information, making volatilebased defences vulnerable to interference [19]. Associational resistance occurs in nature across a range of abiotic variation, including diurnally and seasonally varying temperature and high precipitation as well as drought episodes and changes in atmospheric constituents, such as carbon dioxide. Of these, the prevailing temperature is well known for its role in the control of diffusion and volatility of volatile compounds and their longevity in the atmosphere $[32,33]$. The major $C_{5}$ volatile isoprene is synthesized and emitted in greater amounts under increasing temperatures [34]. For other plant volatiles, such as monoterpenes and sesquiterpenes, the temperature dependence of emission is less obvious. Both physiological and physicochemical regulation takes place in plant foliage and at the leaf-atmosphere interface [35]. In addition, the ability to store these compounds or their precursors in specialized leaf structures (e.g. secretory cavities or trichomes) and their inducibility upon abiotic and biotic stresses creates variance from direct responsiveness to increasing temperature or modelling their species-specific emission potential [20,35]. In the case of sesquiterpenoids, the term semivolatile has been used to describe their less volatile nature and stickiness to surfaces [36, 37]. For such compounds, temperature influences their re-release from surfaces [37]. Despite the role of temperature in volatile emissions, little is known regarding how temperature influences the actual information-carrying capacity of plant volatiles; for example, could associational resistance as mediated by volatiles be substantially improved or hampered by temperature changes?

Brassica plants host a plethora of economically damaging herbivores [12, 38]. Thus, we chose Brassica oleracea 
var. italica (broccoli, B. oleracea from here on)-Plutella xylostella-Cotesia vestalis (Haliday) as the agricultural tritrophic model system to be studied along with the well-defended perennial evergreen shrub Rhododendron tomentosum Harmaja (previously Ledum palustre L.). Rhododendron tomentosum is native to northern latitudes and emits specific semivolatiles [palustrol $\left(\mathrm{C}_{15} \mathrm{H}_{26} \mathrm{O}\right)$, ledol $\left(\mathrm{C}_{15} \mathrm{H}_{26} \mathrm{O}\right)$ and ledene $\left.\left(\mathrm{C}_{15} \mathrm{H}_{24}\right)\right]$ that are capable of being adsorbed to neighbouring foliage [8]; thus, this species represents a strong semivolatile emitter that is abundant in northern environments, making it interesting to test for its potential for providing associational resistance for use in biocontrol. The diamond-back moth P. xylostella L. (Lepidoptera: Yponomeutidae) is a major agricultural pest of Brassica with a global distribution [38]. The moth mass migrates by wind currents to northern regions and is attacked by numerous predators and parasitoids, of which the larval parasitoids, e.g., Cotesia sp. and Diadegma sp. parasitoid wasps, are the most effective for limiting moth population growth [39]. Cotesia vestalis (Haliday) (Hymenoptera: Braconidae), a specialist endoparasitoid parasitizing all of the larval instars of P. xylostella, uses plant-emitted volatiles in host searching [40].

Although we were interested in advancing knowledge on the ecological mechanism and temperature sensitivity of associational resistance, our primary aim was to assess the potential of using $R$. tomentosum for biocontrol in this study. The specific objectives of our study were to assess (1) whether associational resistance towards $P$. xylostella is conferred by exposure to $R$. tomentosum in $B$. oleracea; (2) whether $R$. tomentosum-mediated associational resistance is effective both at night-time and day-time temperatures (12 and $22^{\circ} \mathrm{C}$ upon testing); (3) whether exposure to $R$. tomentosum interferes with indirect defence, i.e., the attraction of the $C$. vestalis parasitoid by host-induced volatiles, of $B$. oleracea; and (4) whether the impact of $R$. tomentosum exposure on indirect defence is affected by temperature $\left(12\right.$ versus $22^{\circ} \mathrm{C}$ ) upon exposure. Experimental set-ups of the study are shown in Figure 1 (see "Methods" for details).

\section{Results}

Verifying the adsorption of $R$. tomentosum volatiles onto neighbouring $B$. oleracea

We first verified that $R$. tomentosum (RT from here on) exposure resulted in semivolatiles being adsorbed and re-released from $B$. oleracea foliage, as previously reported for birch foliage [8]. RT branch emissions were dominated by the sesquiterpene alcohol palustrol, which comprised $43 \%$ of the total volatile emissions (Figure $2 \mathrm{a}$ ). The other main compounds that were detected were $\beta$-myrcene, aromadendrene and ledol (with 34, 10 and $9 \%$ of the total emission, respectively). Palustrol was detected from emission profile of RT-exposed B. oleracea at both exposure temperatures: 6 and $22^{\circ} \mathrm{C}$ (Figure 2b). RT-originating ledol and ledene were emitted only from RT-exposed B. oleracea plants that were exposed at $22^{\circ} \mathrm{C}$. No RT-specific compounds were emitted from the corresponding control B. oleracea plants (Figure $2 \mathrm{~b}$ ). There were no statistically significant differences between control and RT-exposed B. oleracea in the emissions of volatiles detected from both treatments, i.e., $\alpha$-pinene, $\delta$-carene and 1,8-cineole (Figure $2 \mathrm{~b}, P>0.05$ ).

\section{Responses of $P$. xylostella to R. tomentosum-exposed \\ B. oleracea}

Oviposition by $P$. xylostella was lower on RT-exposed than control B. oleracea plants (Figure 3, $\mathrm{F}_{1,36}=13.5$, $P<0.001)$. At $22^{\circ} \mathrm{C}$, there were $38 \%$ and, at $12^{\circ} \mathrm{C}, 36 \%$ less oviposition on RT-exposed plants. A higher number of eggs were laid when the testing temperature during oviposition was $22^{\circ} \mathrm{C}$ compared to $12^{\circ} \mathrm{C}$ (Figure 3, $\left.\mathrm{F}_{1,36}=131.6, P<0.001\right)$.

Plutella xylostella larvae preferred to feed on the control rather than the RT-exposed $B$. oleracea leaves at $12^{\circ} \mathrm{C}$ (Figure $4 \mathrm{a}, P<0.05$ ). This preference was maintained throughout all of the observation time points from $30 \mathrm{~min}$ to $24 \mathrm{~h}$ after release. When the exposure and testing took place at $22^{\circ} \mathrm{C}$, no significant difference in the choice of the larvae between the control and the RT-exposed B. oleracea leaves was detected at any of the observation time points (Figure $4 \mathrm{~b}, P>0.05$ ).

The leaf area that was consumed by $P$. xylostella larvae was higher in the control than in the RT-exposed B. oleracea leaves at $12^{\circ} \mathrm{C}$ (Figure $5 \mathrm{a}, t=5.75, \mathrm{df}=41$, $P<0.001)$. There was no difference in the amount of leaf damage between the treatments at $22^{\circ} \mathrm{C}(t=1.61$, $\mathrm{df}=38, P=0.116$ ). The number of feeding holes on RTexposed B. oleracea was smaller than that on control $B$. oleracea leaves at $12^{\circ} \mathrm{C}$ (Figure $5 \mathrm{~b}, t=-3.26, \mathrm{df}=41$, $P=0.002)$, whereas no difference between treatments was found when the test took place at $22^{\circ} \mathrm{C}(t=-0.95$, $\mathrm{df}=39, P=0.347$ ).

Host location by $C$. vestalis: role of $R$. tomentosum exposure Cotesia vestalis females showed no preference for intact B. oleracea over RT volatiles (Figure $6, \chi^{2}=0.27$, $P=0.602$ ), and only $33 \%$ of the parasitoids made a choice in this behavioural test comparison. The functioning of the B. oleracea-P. xylostella-C. vestalis tritrophic interaction was verified by the greater attraction of $C$. vestalis females towards host-damaged rather than intact $B$. oleracea volatiles $\left(\chi^{2}=3.90, P=0.048\right)$. The parasitoids also preferred host-damaged, RT-exposed $B$. oleracea over intact plants when the exposure took place at day-time 


\section{Experimental set-ups of the study}

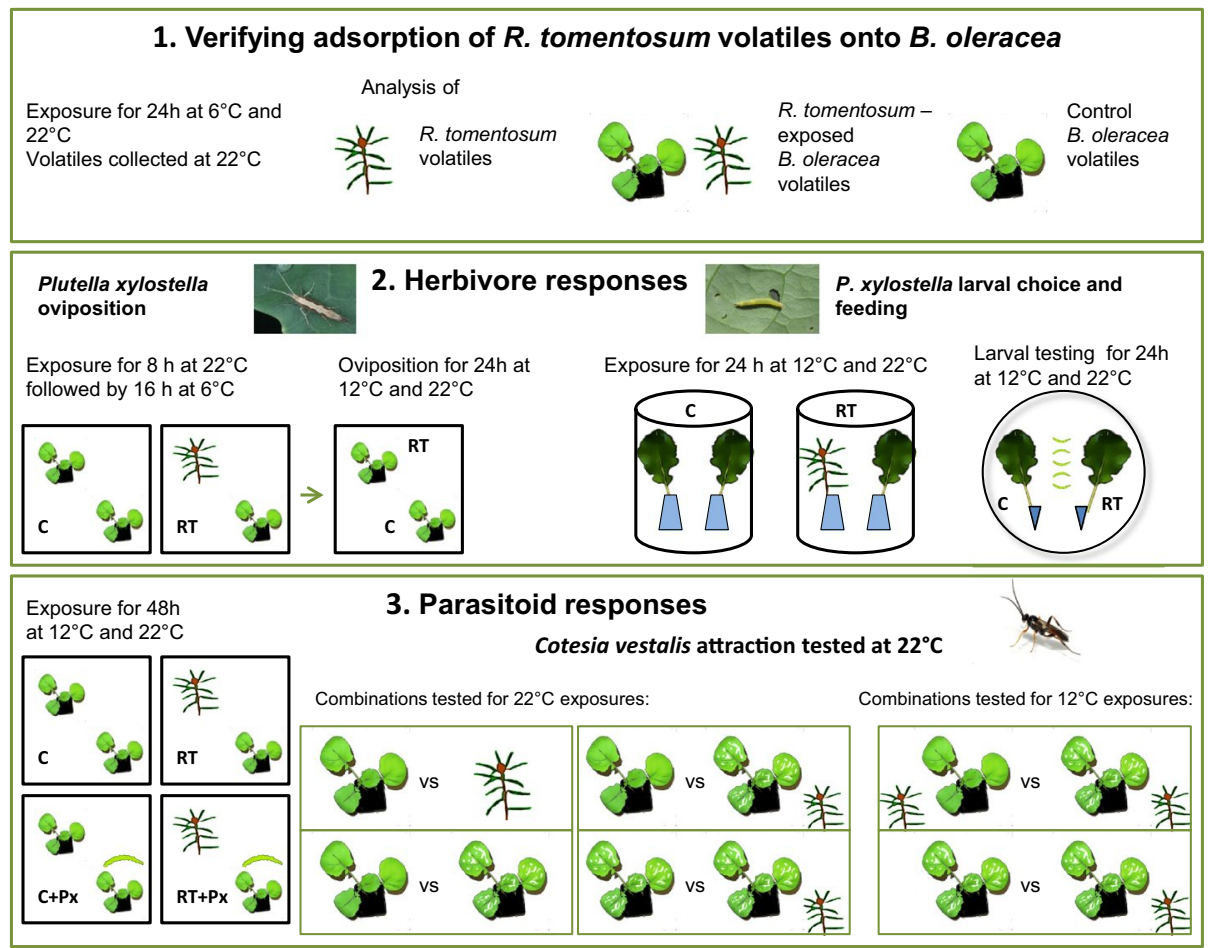

Figure 1 Experimental set-ups of the study. The study consisted of three parts testing plant, herbivore and parasitoid responses towards $R$. tomentosum (RT) exposure. Temperatures used in each part varied according to the response to be tested, and were representative of boreal environment variation in early summer night-time and day-time temperatures. In Part 1 (volatile analysis), a $6^{\circ} \mathrm{C}$ night-time minimum temperature versus day-time $22^{\circ} \mathrm{C}$ was used in order to reveal whether a temperature-dependent adsorption-desorption process of RT semivolatiles occurs on $B$. oleracea. Herbivore oviposition in Part 2 was compared at average day-time $\left(22^{\circ} \mathrm{C}\right)$ versus average night-time $\left(12^{\circ} \mathrm{C}\right)$ temperatures, with equal initial RT exposure (day-time $22^{\circ} \mathrm{C}$ followed by minimum night-time temperature of $6^{\circ} \mathrm{C}$ ). Larval choice and feeding was tested at stabile 12 and $22^{\circ} \mathrm{C}$ temperatures to allow comparison for a $24 \mathrm{~h}$ period of feeding at night-time versus day-time temperatures along with temperature-representative RT exposures. In Part 3, the day-active parasitoids were tested at $22^{\circ} \mathrm{C}$, with the prior RT exposure conducted at average day-time $\left(22^{\circ} \mathrm{C}\right)$ and night-time $\left(12^{\circ} \mathrm{C}\right)$ temperatures. $\mathrm{Px}=$ P.xylostella. Photos of P. xylostella and C. vestalis: Jarmo Holopainen.

temperature $\left(22^{\circ} \mathrm{C}\right)\left(\chi^{2}=4.83, P=0.028\right)$. No preference by $C$. vestalis was observed between host-damaged and host-damaged RT-exposed B. oleracea at this temperature $\left(\chi^{2}=1.11, P=0.292\right)$. The parasitoid choosing rates were greater than $60 \%$ in all three assays with host-damaged $B$. oleracea as an odour source.

When using plants that were exposed to $\mathrm{RT}$ at $12^{\circ} \mathrm{C}, C$. vestalis preferred host-damaged RT-exposed $B$. oleracea plants to intact RT-exposed plants with a marginal statistical significance (Figure 6, $\chi^{2}=3.81, P=0.067$ ). The parasitoid had no preference for host-damaged over hostdamaged RT-exposed B. oleracea $\left(\chi^{2}=0.24, P=0.743\right)$.

\section{Discussion}

Our results revealed that RT exposure reduced the oviposition and larval feeding of a key pest herbivore of cruciferous plants: the diamondback moth $P$. xylostella on B. oleracea. A colder temperature $\left(12^{\circ} \mathrm{C}\right)$ upon exposure was integral to the increase in larval resistance. In addition, indirect defence, evaluated here as the attraction of the specialist parasitoid C. vestalis by host-induced volatiles, remained persistent despite RT exposure, although indications for a reduced response were found when the exposure took place at a colder temperature $\left(12^{\circ} \mathrm{C}\right)$.

\section{Associational resistance via $R$. tomentosum: mechanisms of action and potential for biocontrol}

The provision of associational resistance by RT volatiles, as previously suggested for a natural neighbour (Betula sp.) [8], was confirmed in this study on a Brassica crop species and towards a damaging global pest: the diamondback moth. In extracts of RT, with ledene, ledol and palustrol forming the majority of the composition, repellence has been reported towards various arthropods [41, 42]. Our finding that exposure via air alone was sufficient to render increased resistance towards both adult and 

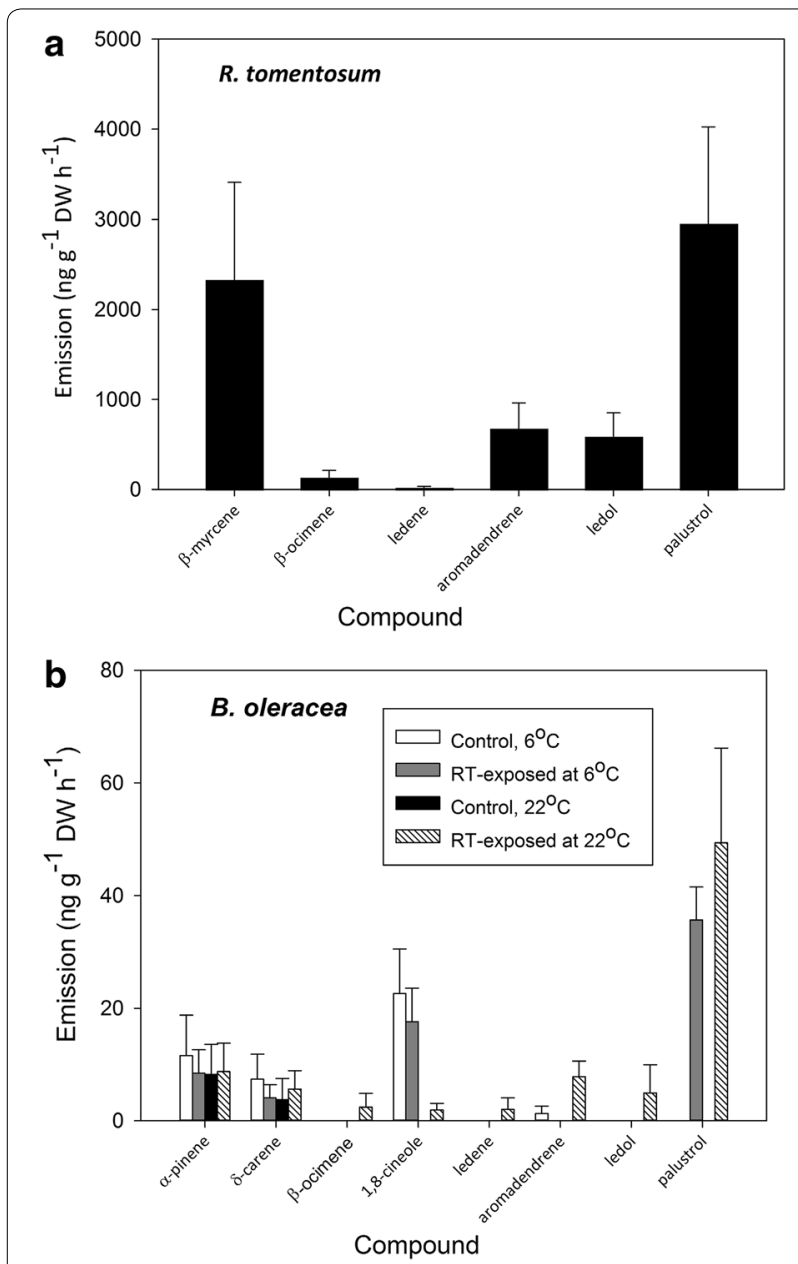

Figure 2 Volatile emission from Rhododendron tomentosum (a) and control and $R$. tomentosum-exposed Brassica oleracea $(\mathbf{b})$. The mean \pm SEM emission of individual volatile compounds detected are shown. Brassica oleracea plants were exposed to $R$. tomentosum for $24 \mathrm{~h}$ at 6 or $22^{\circ} \mathrm{C}$, and volatile emissions were collected post-exposure at $22^{\circ} \mathrm{C} . n=3$ in $(\mathbf{a})$ and $n=4$ in (b) for both exposure temperatures.

larval stages of $P$. xylostella, with no need for the physical application of the compounds, suggests that RT could be a pest-suppressive intercrop for Brassica.

Our study is not able to determine whether the increased resistance acts as an olfactory, as an contact cue or both. Furthermore, the mode of action for RT exposure leading to associational resistance on $B$. oleracea also remains an open question: the observed impacts could stem from RT volatiles that are adsorbed onto and re-released from $B$. oleracea leaves or from B. oleracea volatiles induced by RT exposure. Because B. oleracea intrinsic volatile emission was low and there were no indications of other compounds being altered in the profile after RT exposure than the RT-specific semivolatiles, which can be adsorbed onto foliage [8], the latter

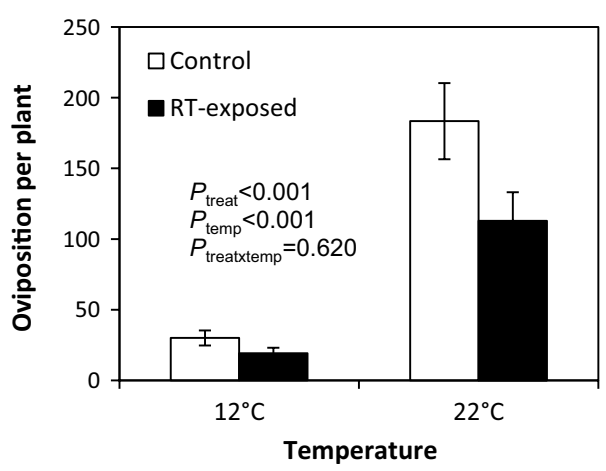

Figure 3 Oviposition by Plutella xylostella on control and $R$. tomentosum-exposed Brassica oleracea at 12 and $22^{\circ} \mathrm{C}$. The values represent the mean number of $P$. xylostella eggs per plant \pm SEM based on three independent experiments ( $n=4$ in each experiment). $P$ values for the main effects of treatment and temperature and their interaction are shown.
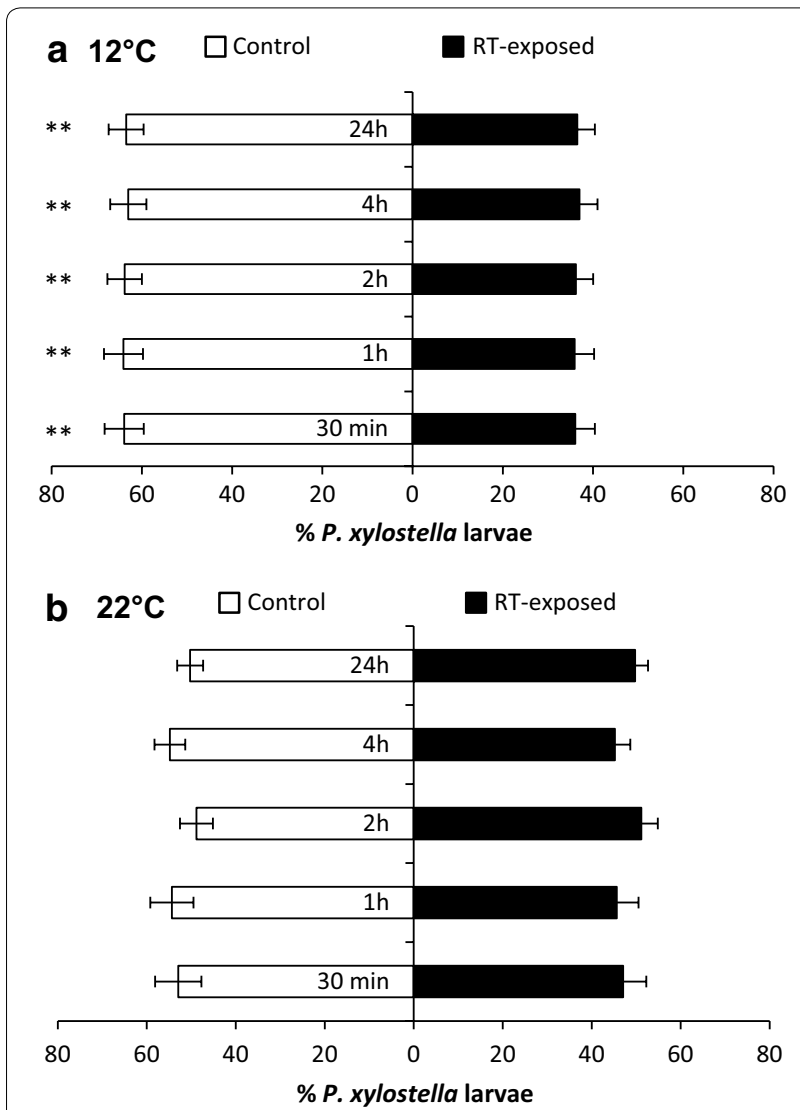

Figure 4 Plutella xylostella larval choice towards control versus $R$. tomentosum-exposed Brassica oleracea at 12 and $22^{\circ} \mathrm{C}$. The percentage distribution (mean $\pm \mathrm{SEM}$ ) of larvae in choice tests performed at $12^{\circ} \mathrm{C}(\mathbf{a})$ and $22^{\circ} \mathrm{C}(\mathbf{b})$ is shown. Each replicate includes the choices (positioning on either leaf) of five individual larvae. $n=20-21$ in both of the independent replicate experiments for which the results are summarized here. Statistically significant differences in larval choice are indicated by asterisks (**P $<0.01)$. 

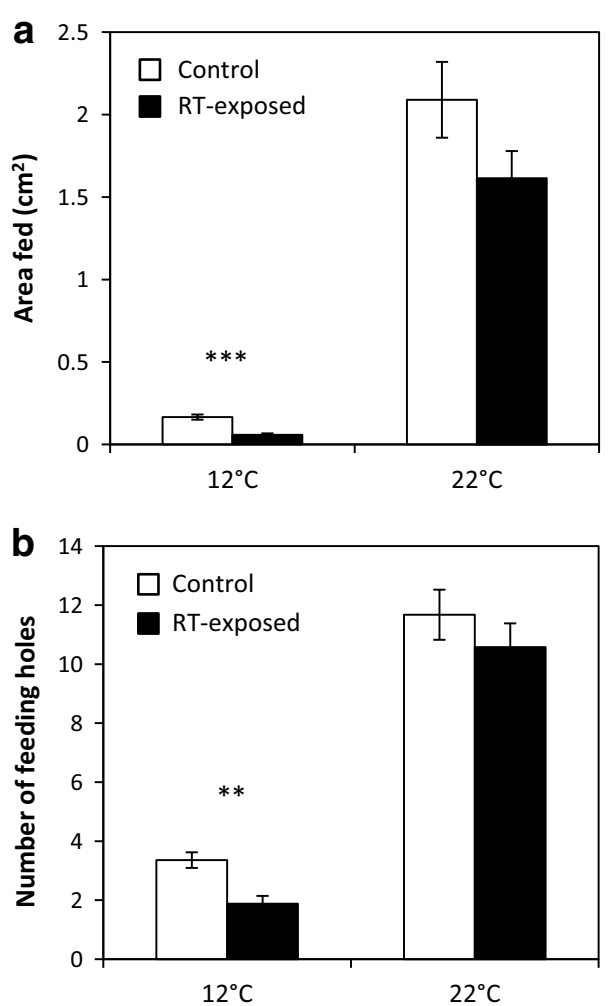

Figure 5 Leaf area fed and feeding holes on control and $R$. tomentosum-exposed Brassica oleracea. The amount of leaf area fed at $12^{\circ} \mathrm{C}$ and at $22^{\circ} \mathrm{C}(\mathbf{a})$ and the number of feeding holes made at $12^{\circ} \mathrm{C}$ and at $22^{\circ} \mathrm{C}$ (b) (mean \pm SEM) by five Plutella xylostella larvae over $24 \mathrm{~h}$ on control and $R$. tomentosum (RT)-exposed $B$. oleracea leaves are shown. $n=20-21$ in both of the independent replicate experiments for which the results are summarized here. Statistically significant differences between treatments are indicated by asterisks ${ }^{* *} P<0.01$, $\left.{ }^{* * *} P<0.001\right)$.

hypothesis is not supported. Therefore, RT volatiles are likely candidates for passively providing increased resistance. These persistent compounds, which are emitted in large amounts by RT, could disguise host location, oviposition or feeding stimulation cues, such as glucosinolate break-down products for the specialist pest $P$. xylostella [39]. Alternatively, these compounds might cause direct repellence $[41,42]$. Thus, follow-up laboratory work with synthetic palustrol, ledol and ledene is needed to reveal the acting mechanism for RT-exposure-mediated associational resistance.

The potential importance of RT semivolatiles is further supported by the observed temperature dependence of the resistance towards larval feeding: at $12^{\circ} \mathrm{C}$, the RT specific semivolatiles are stuck on surfaces. In [37], an effort to establish artificial broccoli leaves, i.e., a wax layer on a microscope slide, for detecting adsorption of induced volatiles, showed how induced sesquiterpenes in particular were adsorbed onto the wax and then re-released upon increasing temperature. As epicuticular wax is the surface encountering RT volatiles under aerial exposure, their mode of action could involve an interaction with wax chemicals. Plutella xylostella prefers to oviposit on glossy versus waxy leaves, and high epicuticular wax bloom makes cabbage more resistant for the pest [43]. The chemical composition of the wax varies between the types, i.e., the proportion of alkanes and ketones is lower, while that of fatty acids and triterpenoids is larger on glossy wax type leaves [44]. In addition, also P. xylostella larvae are impacted by the wax properties: they spend more time searching and less time feeding on glossy cabbages [44]. Thus, one hypothesis for the mechanism for the partly temperature-dependent RT-mediated resistance in our study is the chemical compositional changes that are induced by RT volatiles in B. oleracea leaf wax.

In biocontrol, companion crops with reported impacts on agriculturally important herbivores have often included aromatic-volatile-emitting herbs [45, 46], indicating that the potential semivolatile characteristics that their main volatiles possess might be more generally important for the effectiveness of associational resistance. However, the effectiveness of herb intercropping impacting herbivore abundance varies $[12,46]$. Additional variability complicating understanding of the role of volatiles for associational resistance is created by the differential behavioural patterns that are likely observed for generalist versus specialist herbivores [12]. In addition, there is ample variation by species in utilising volatiles in host location [6] in comparison to other cues, such as phenotypic differences acting as physical barriers or visual cues $[17,47]$. Our finding that temperature impacts the effectiveness of associational resistance emphasizes the need to include a more detailed analysis of changes in volatile emissions under natural temperature variations considering their properties affecting their volatility or adsorption onto foliage [36, 37]. The volatile profile of a plant species is a genetically regulated property that is important to be assessed when developing agricultural applications based on associational resistance $[15,16]$.

\section{Persistent indirect defence: does high olfactory specificity at upper trophic levels protect against interference?}

Indirect defence, assessed here for the attraction of a specialist parasitoid C. vestalis to host-damaged B. oleracea volatiles, was not interfered with by RT exposure at $22^{\circ} \mathrm{C}$. The attraction was slightly reduced following the $12^{\circ} \mathrm{C}$ exposure, indicating that RT exposure might become more meaningful at morning and late evening hours when the temperature decreases. The greater tendency for the studied herbivore to be influenced by RT exposure rather than its natural enemy is supported by a field study in which there was no difference in parasitism, but 


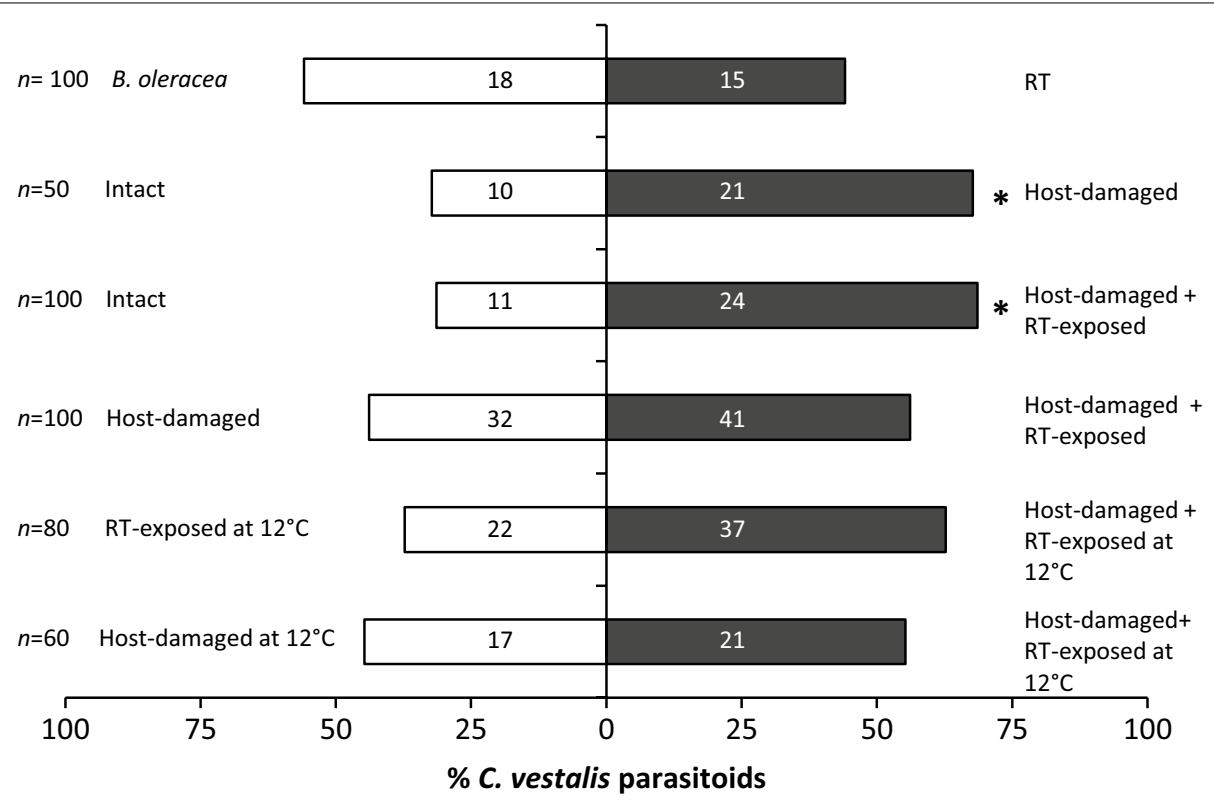

Figure 6 Orientation of parasitoid Cotesia vestalis in Y-tube olfactometer assays. The selection of the individually tested parasitoids (\% of parasitoids making a selection) towards either of the odour sources in a two-arm olfactometer is shown. Intact, host-damaged and R. tomentosum (RT)-exposed refer to treatments of B. oleracea plants. Host-damaged plants experienced $48 \mathrm{~h}$ of Plutella xylostella L. larval feeding and RT-exposed plants neighboured a potted $R$. tomentosum plant for $48 \mathrm{~h}$ before testing at the temperature shown. The total number of parasitoids tested $(n)$ and number of individuals making a selection towards the odour sources are also reported. Statistically significant differences in the selections are indicated by asterisks $\left({ }^{*} P<0.05\right)$.

densities of larval and pupal stages of P. xylostella were reduced in the mixed cropping of cabbage and coriander [47]. The ability of a non-host scent to act towards both a herbivore and its natural enemy, has been reported for a Yeheb (Cordeauxia edulis) plant extract [48] which at the same time attracted C. vestalis and repelled P. xylostella. We found no such attracting effect from RT towards $C$. vestalis that could have led to synergy in P. xylostella biocontrol.

To our knowledge, the passive adsorption of heterospecific species emitted volatiles, and the resulting associational resistance has not been considered in the context of disturbing indirect defence earlier. However, the abundance and foraging efficiency of parasitoids have been studied in complex versus less complex environments [49-51], with chemical complexity hypothesized to be one influencer of arthropod abundance [50]. The parasitoid Diadegma semiclausum entered a Sinapis-Brassica intercrop faster than a Hordeum-Brassica intercrop, but took more time to find host there [49], indicating that species composition is meaningful, even though the cocrop volatiles were not analysed, permitting a comparison of volatile-mediated and other cues. In [51], as the habitat complexity increased, stronger host cues for $C$. glomerata host finding were concluded to be required. In addition, in [52], C. glomerata, with a wider host range compared to that of the more specialised Cotesia rubec$u l a$, was less effective in host finding in mixed cultures of B. oleracea and potato. In a laboratory study with volatile interference introduced by isoprene, another parasitoidspecific response was found: isoprene interfered with the host location in D. semiclausum but not in C. rubecula [22]. The mixing of non-host herbivore-induced cabbage volatiles and host-induced volatiles of bean did not interfere with the attraction of specialist predatory mites to prey [53]. In [54], non-host volatiles were verified to be sensed by a predaceous beetle, suggesting the ability of non-host volatiles in particular to hamper tritrophic interactions. It could be that more specialised parasitoids, such as $C$. vestalis in our study, are less sensitive to disturbance than herbivore natural enemies with a wider host range and thus a higher tendency for adaptation. Thus, it will be interesting to test in the future whether the specialization of the tritrophic interaction plays a key role in the sensitivity to neighbour plant semivolatile interference.

\section{Temperature as a mediator of associational resistance}

Temperature varies greatly in nature and in agroecosystems, diurnally, seasonally and regionally, impacting plant phenology and insect activity and, thus, their interactions [55]. Night-time temperatures often fall close to $10^{\circ} \mathrm{C}$ in 
boreal regions (the natural habitats of RT) in the summer. Thus, nocturnal and day-active herbivores might be variably affected by exposure to RT semivolatiles and their presence in air versus foliage. Plutella xylostella moths are night-active, and their oviposition peaks at dusk, but light during night (as typical for boreal summer) does not inhibit oviposition [39]. Increasing temperature hastens the duration of the life cycle of $P$. xylostella as well as its oviposition and larval feeding activity [39]. The reported equal reduction in oviposition on RT-exposed plants under both studied temperatures suggests a diurnally persistent increase in resistance towards $P$. xylostella. Oviposition is agronomically important because it determines the initial acceptance of the host plant. Plutella xylostella does not oviposit on non-host plants as it relies on a variety of chemical and physical host recognition cues [56]; RT exposure seems to interfere with one or several of these.

Our result on resistance towards $P$. xylostella larval feeding emerging at a lower temperature is less beneficial for the plant as P. xylostella feeding increases by temperature [39]. However, the finding is interesting with regards to hypothesizing a regulating role for temperature in semivolatile-mediated associational resistance. The temperature dependence of the volatiles acting might offer one hypothetical explanation for why aromatic herbs that are rich in sesquiterpenes have often shown success, but also failures in providing resistance in mixed cropping $[12,14-16]$. To reveal whether this is the case, the leaf-air interface dynamics of the specific volatiles acting should be studied in detail under temperature regimes.

Another consideration in the long-term effectiveness of associational resistance as conferred by the neighbour's volatiles is that the non-static nature of the signal, mediated by temperature, might also help slow both the adaptation of herbivores to the scent [57] and the evolution of breaking host plant resistance by herbivores. Temperature control renders the signal most effective at certain time periods only, partly resembling the mode of function of inducible defences [23]. Both mechanisms might be ecologically and even evolutionarily supported by the dynamic nature of signal appearance in addition to saving resources from the receiver.

The overall effect of temperature variations on the plant-herbivore dynamics in a multitrophic system depends on the comparative responses of herbivores and their natural enemies. The temperature sensitivity of different trophic-level insects varies [58]; parasitoids and predators are generally assumed to be more responsive than their prey, as they rely more on mobility in prey searching and are physiologically more responsive to temperature. Upon temperature changes, herbivores, on the other hand, face bottom-up changes in plant host quality, show direct physiological and reproductional responses [55], plus are confronted by altered top-down control from natural enemies [59]. The parasitoid studied here, C. vestalis, oviposits upon photophase with optimal temperature for parasitism at $20-35^{\circ} \mathrm{C}$ [60]. Thus, our finding that the host location by $C$. vestalis was not interfered with by $\mathrm{RT}$ exposure at $22^{\circ} \mathrm{C}$ suggests that using RT for $P$. xylostella biocontrol should not compromise the ability of $C$. vestalis to locate host on B. oleracea. The slightly reduced attraction towards plants that were exposed to $\mathrm{RT}$ at $12^{\circ} \mathrm{C}$ suggests, however, that exposure to RT might affect the interaction at low temperatures such as during early morning.

\section{Conclusions}

The ability of RT exposure, earlier discovered to render associational resistance in nature, to influence Brassica herbivore oviposition and larval feeding encourages further testing of its potential for biocontrol. The generality of our finding on the regulatory role of temperature on associational resistance should be tested in the future on natural and agricultural plant systems varying in plant volatile composition (acknowledging the differential role of semivolatile versus more volatile compounds). Additionally, the level of specialisation and the use of the visual, olfactory and chemoreceptor cues of targeted herbivores should be studied together to distinguish the role of volatile-based and other neighbouring potentiated defences. Finally, our study emphasizes that for developing biocontrol applications based on associational resistance, more attention needs to be paid to the compatibility of plant defences with herbivore diurnal behaviour and times of activity as well as that of their natural enemies.

\section{Methods}

Plants, herbivores and natural enemies

Brassica oleracea var. italica (broccoli) cv. Lucky seedlings were grown from seed in 0.661 pots (4 plants in each, mixture 2:1:1 of fertilized compost, NPK 100:30:200 $\mathrm{mg}^{-1}$ : B2 peat NPK 110:40:220 $\mathrm{mg} \mathrm{l}^{-1}$ : sand) in a greenhouse (temperature $20 / 16^{\circ} \mathrm{C}$ day/night) and used at approximately 3 weeks of age for experiments. $R$. tomentosum (RT) branches that were collected from a natural habitat in Suonenjoki, Finland $\left(62^{\circ} 38^{\prime} 42.683^{\prime \prime} \mathrm{N}\right.$, $27^{\circ} 3^{\prime} 55.383^{\prime \prime} \mathrm{E}$ ) and stored at $6^{\circ} \mathrm{C}$ prior to use if necessary, were used in the exposure treatments. Potted greenhouse-grown RT plants (seed origin: natural habitat in Neulaniemi, Kuopio, grown in 3:1 peat:sand) of circa 20 $\mathrm{cm}$ in height were used in the Y-tube olfactometer tests. The P. xylostella larvae and adults and C. vestalis parasitoids that were used in the experiments originated from laboratory populations maintained on B. oleracea var. italica $\left(20-25^{\circ} \mathrm{C}\right.$ temperature and $16 \mathrm{~L}: 8 \mathrm{D}$ photoperiod) at the University of Eastern Finland. 


\section{Volatile collection and analysis}

For exposure, four B. oleracea pots (with four 21-days-old plants/pot) were enclosed in insect cages $(33 \times 33 \times 60 \mathrm{~cm}$, with two sides covered with a fabric mesh) with 15 cut hibernating RT branches (collected right before the experiments from the natural habitat) that had their stems in water-filled 250-ml decanter bottles. Control cages had an equal set-up but hosted no RT branches. The cages were placed at $6^{\circ} \mathrm{C}$ (cold room) and $22^{\circ} \mathrm{C}$ (a laboratory fume hood) under low light (approximately $150 \mu \mathrm{mol} \mathrm{m} \mathrm{m}^{-2} \mathrm{~s}^{-1}$ ). The colder night temperature was used to mimic minimum boreal early summer temperatures. After $24 \mathrm{~h}$, the plants were removed from exposure, and the volatiles were collected at $22^{\circ} \mathrm{C}$ using a dynamic bag enclosure method. The RT branch emissions were collected from three branches at $22^{\circ} \mathrm{C}$ to determine their characteristic emission profile.

For volatile collection, the entire shoot of a five-leaf stage broccoli plant or RT branch was enclosed inside pre-cleaned (heating for $1 \mathrm{~h}$ at $120^{\circ} \mathrm{C}$ ) multipurpose cooking bags (polyethylene terephthalate (PET), $25 \times 55 \mathrm{~cm}$ in size, Look, Terinex Ltd, UK), and the bag opening was tied around the base of the stem with a piece of thin garden wire. After the enclosure of the plant, air that had been filtered through charcoal and a $\mathrm{MnO}_{2}$ scrubber were pumped into bags through an opening in one of the top corners of the PET bags at a flow rate of $600 \mathrm{ml} \mathrm{min}^{-1}$ for $10 \mathrm{~min}$ to flush out residual contaminants. The sampling line was inserted into another corner of the bag and tied with a wire. After fixing the lines, the inflow rate was reduced to $300 \mathrm{ml} \mathrm{min}{ }^{-1}$, and the volatile emissions were sampled in stainless steel tubes that were filled with $150 \mathrm{mg}$ of Tenax TA adsorbent (Supelco, Bellefonte, PA USA) for $30 \mathrm{~min}$ at the rate of about $200 \mathrm{ml} \mathrm{min}^{-1}$ with a vacuum pump (Thomas $500212 \mathrm{~V}$ DC). An equal light level (approximately $300 \mu \mathrm{mol} \mathrm{m} \mathrm{m}^{-1} \mathrm{~s}^{-1}$ ) was provided by placing two lamps (Lival Shuttle Plus, Lival Oy, Sipoo, Finland with Osram Delux F, 24W fluorescent lamps, Osram AG, Munich, Germany) on both sides of each plant. Sample tubes were sealed with Teflon-coated brass caps immediately after collection and stored in the refrigerator until analysis. The plant biomass was oven-dried $\left(60^{\circ} \mathrm{C}\right)$ to determine the dry weights of the plants.

The plant volatile samples were analysed by a gas chromatograph-mass spectrometer (GC type 6890, MSD 5973: Hewlett Packard; Wilmington, DE, USA) as described in [61]. The trapped compounds were desorbed with a thermal desorption unit (Perkin-Elmer ATD400 Automatic Thermal Desorption system) at $250^{\circ} \mathrm{C}$ for $10 \mathrm{~min}$, cryofocused at $-30^{\circ} \mathrm{C}$ and injected onto a HP-5 capillary column $(50 \mathrm{~m} \times 0.2 \mathrm{~mm}$ i.d. $\times 0.5 \mu \mathrm{m}$ film thickness, Hewlett-Packard) with helium as a carrier gas. The oven temperature programme was held at $40^{\circ} \mathrm{C}$ for
$1 \mathrm{~min}$ and then increased to $210^{\circ} \mathrm{C}$ at a rate of $5^{\circ} \mathrm{C} \mathrm{min}-1$ and finally to $250^{\circ} \mathrm{C}$ at a rate of $20^{\circ} \mathrm{C} \mathrm{min}{ }^{-1}$. The compounds were identified and quantified by comparing the spectra of external standards for available compounds and the Wiley library (John Wiley \& Sons, Ltd, Chichester, UK). The emission rates were calculated as emission per dry weight (DW) per hour.

\section{Oviposition by $P$. xylostella moths}

RT exposure was identical in the set-up as used for the plants for volatile analysis. Here, the exposure was maintained (as well as the corresponding control plants with no RT branches inside cages) in fume hoods at $22^{\circ} \mathrm{C}$ for the previous day $\left(8 \mathrm{~h}\right.$ ) followed by $16 \mathrm{~h}$ at $6^{\circ} \mathrm{C}$ (cold room, representing typical early summer night-time minimum temperature) until the start of the oviposition experiment. All of the plants were equally exposed to assure equal initial amounts of potentially adsorbed semivolatiles by exposure, revealing solely day-time versus nighttime temperature differences for oviposition.

The oviposition in control and RT-exposed B. oleracea was experimented in $2.6 \mathrm{~m}^{3}$ temperature-controlled growth chambers (described in [62]) at temperatures of 12 and $22^{\circ} \mathrm{C}$ (mimicking average boreal night-time and day-time temperatures, respectively) and a 22L:2D photoperiod with approximately $250 \mu \mathrm{mol} \mathrm{m}^{-2} \mathrm{~s}^{-1}$ light level. One control and one RT-exposed B. oleracea pot were enclosed in each of the four replicate insect cages under both of the temperature treatments. Thirty P. xylostella moths were randomly selected by the expectation of the 50:50 female:male ratio (population well stabilised to assure that both sexes were present and allowing mating as in nature) [48] and released into each cage. After $24 \mathrm{~h}$, the $\mathrm{B}$. oleracea plants were removed from cages and stored at $6^{\circ} \mathrm{C}$ until egg counting. Three independent replicate experiments were carried out.

\section{Host choice and feeding by $P$. xylostella larvae}

For herbivore choice tests, the exposure of $B$. oleracea leaves to RT volatiles was conducted in 1.5-1 glass containers holding two $30-\mathrm{ml}$ glass vials approximately $3 \mathrm{~cm}$ apart, as in [8]. Ten to eleven independent systems were built per replicate experiment (two independent replicate experiments were conducted for both temperatures), each having two $B$. oleracea leaves in one vial and either an RT branch (RT-exposure treatment) or a B. oleracea leaf (control) in the other vial. The exposures and the following choice tests took place for $24 \mathrm{~h}$ for each part in a laboratory fume hood $\left(22^{\circ} \mathrm{C}\right)$ and a cold room $\left(12^{\circ} \mathrm{C}\right)$, mimicking average boreal early summer day-time and night-time temperatures, respectively.

For choice tests, the petioles of $B$. oleracea leaves (one each from control and exposed system set-ups) 
were inserted with forceps into water-filled 1.5-ml Eppendorf tubes through a hole in the cap and placed into 13-cm-diameter glass Petri dishes that were lined with filter paper. An equal light level (approximately $300 \mu \mathrm{mol} \mathrm{m}^{-1} \mathrm{~s}^{-1}$ ) was provided by placing four fluorescent lamps above the dishes. The position of the control and exposed leaves was alternated in order to remove any remaining inequality in light conditions. Five 2nd instar P. xylostella larvae were released in the middle of each dish, and the location of the herbivores on each leaf was recorded at $30 \mathrm{~min}, 1,2,4$ and $24 \mathrm{~h}$. After $24 \mathrm{~h}$, the larvae were removed, and each leaf was photographed to determine the number of feeding holes and the leaf area that was consumed by the larvae in pixels, which was converted to square centimetres using Adobe Photoshop Elements 2.0 (Adobe Systems Incorporated, Wilmington, DE, USA).

\section{Host location by $C$. vestalis females}

The potential interference on the olfactory orientation of $C$. vestalis towards $P$. xylostella-induced $B$. oleracea volatiles by RT was tested using $48 \mathrm{~h}$ exposure treatments at 22 and $12^{\circ} \mathrm{C}$ (average boreal early season day-time and night-time temperatures, respectively). For RT exposure treatments, B. oleracea plants in pots (4 per pot, 21 days old) were placed within a $10-\mathrm{cm}$ distance of a RT plant inside plastic insect cages (as previously described) in a fume hood at $22^{\circ} \mathrm{C}$ or a cold room at $12^{\circ} \mathrm{C}$. For host herbivore damage treatments, a total of three 4th instar and three 2nd instar P. xylostella larvae were placed in each pot of B. oleracea. An equal number of same-aged plants were used for the control treatment. The larvae were allowed to feed for $48 \mathrm{~h}$, after which they were removed immediately prior to behavioural tests.

The plants (one pot per enclosure) with the soil and pot covered with aluminium foil were placed inside 22-1 glass vessels immediately after ending the treatments and used as odour sources to assess the parasitoid orientation in a Y-tube olfactometer. The plants that were exposed at $12^{\circ} \mathrm{C}$ were put inside the vessels at $12^{\circ} \mathrm{C}$ and immediately before testing transferred to the laboratory where olfactometry tests were conducted with $C$. vestalis at $22^{\circ} \mathrm{C}$.

Four comparisons were tested using plant treatments at $22^{\circ} \mathrm{C}$ : (1) intact $B$. oleracea versus $\mathrm{RT}$ (to determine whether $C$. vestalis is intrinsically affected by RT volatiles); (2) intact B. oleracea versus host-damaged B. oleracea (to verify the functioning of the system for testing orientation of the parasitoid to host damage); (3) intact $B$. oleracea versus host-damaged RT-exposed B. oleracea (to determine whether RT exposure disturbs the olfaction of induced volatiles); and (4) host-damaged B. oleracea versus host-damaged RT-exposed B. oleracea (to determine whether $C$. vestalis is able to discriminate between these). With the plants from $12^{\circ} \mathrm{C}$ treatments, two comparisons were tested: (5) RT-exposed B. oleracea versus hostdamaged RT-exposed B. oleracea (to determine whether RT exposure at $12^{\circ} \mathrm{C}$ disrupts host finding) and (6) hostdamaged B. oleracea versus host-damaged RT-exposed $B$. oleracea (testing the ability to discriminate between these after exposure at $12^{\circ} \mathrm{C}$ ).

Two-to-five days old mated female parasitoids, which were provided with a minimum 2-h-long learning period (improving the responsiveness of the parasitoid, [40]) with a $P$. xylostella-infested $B$. oleracea plant prior to testing, were used in the Y-tube olfactometer assays. For each test, female $C$. vestalis parasitoids were introduced individually downwind at the opening of the Y-tube, with arms connected to the two 22-1 glass vessel odour sources (see [40] for details). A choice was recorded when the parasitoid had reached the last third of either arm and stayed there for more than $3 \mathrm{~s}$. The maximum time for recording a choice was $5 \mathrm{~min}$. Ten individuals were tested with the same odour sources, and each parasitoid was tested only once. A total of 50-100 parasitoids were tested for each comparison.

\section{Statistical analyses}

All data were checked for normality and equality of variances before statistical analysis and log-transformed to meet the requirements when needed. Differences in concentrations of individual volatile compounds (detected in both of the treatments) were analysed with independent samples $t$ tests, separately for the two exposure temperatures. Plutella xylostella oviposition data were analysed for the main effects of treatment, temperature and their interaction, including the experiment as a random effect, using a mixed model for logtransformed values. Paired samples $t$ tests were used to test $P$. xylostella larval choice, leaf area removed and the number of feeding holes separately for the two temperatures. Both of the replicate experiments were analysed together. Chi square tests (comparison to the binomial distribution) were used to analyse the Y-tube olfactometer choice test data. All tests were performed with SPSS 14.0 for Windows (SPSS Inc., Chicago, IL, USA).

\section{Abbreviation \\ RT: Rhododendron tomentosum (Harmaja).}

\section{Authors' contributions}

SJH and JKH designed the study. SJH participated in, supervised and analysed the larval choice tests and parasitoid orientation assays, and drafted the manuscript. TNTB performed the oviposition tests and participated in their analysis. MMM carried out the volatile collections and analysed the results. JKH participated in and supervised oviposition tests and parasitoid orientation assays and their analysis. All authors read and approved the final manuscript. 


\section{Author details}

${ }^{1}$ Natural Resources Institute Finland (Luke), Management and Production of Renewable Resources, Production Systems, Lönnrotinkatu 5, Fl-50100 Mikkeli, Finland. ${ }^{2}$ Department of Environmental Science, University of Eastern Finland, Kuopio Campus, P.O. Box 1627, FI-70211 Kuopio, Finland.

\section{Acknowledgements}

We thank Evele Eposi Grace and Rajendra Prasad Ghimire for assistance in the experiments. Financial support from the Academy of Finland (projects no. 133322, 257965 and 292783) and the University of Eastern Finland (spearhead project $(\mathrm{ABI})$ is acknowledged.

\section{Compliance with ethical guidelines}

\section{Competing interests}

The authors declare that they have no competing interests.

Received: 19 January 2015 Accepted: 13 May 2015

Published online: 29 May 2015

\section{References}

1. Tahvanainen JO, Root RB (1972) The influence of vegetational diversity on the population ecology of a specialized herbivore, Phyllotreta cruciferae (Coleoptera: Chrysomelidae). Oecologia 10:321-346

2. Atsatt PR, O'Dowd DJ (1976) Plant defense guilds. Science 193:24-29

3. Root RB (1973) Organization of a plant-arthropod association in simple and diverse habitats: The fauna of collards (Brassica oleracea). Ecol Monogr 43:95-124

4. Altieri MA, Whitcomb WH (1979) Potential use of weeds in the manipulation of beneficial insects. HortSci 14:12-18

5. Dicke M (2000) Chemical ecology of host-plant selection by herbivorous arthropods: a multitrophic perspective. Biochem Syst Ecol 28:601-617

6. Bruce TJA, Wadhams LJ, Woodcock CM (2005) Insect host location: a volatile situation. Trends Plant Sci 10:269-274

7. Karban R (2011) The ecology and evolution of induced resistance against herbivores. Funct Ecol 25:339-347

8. Himanen SJ, Blande JD, Klemola T, Pulkkinen J, Heijari J, Holopainen JK (2010) Birch (Betula sp.) leaves adsorb and re-release volatiles specific to neighbouring plants - a mechanism for associational herbivore resistance? New Phytol 186:722-732

9. Barbosa P, Hines J, Kaplan I, Martinson H, Szczepaniec A, Szendrei Z (2009) Associational resistance and associational susceptibility: having right or wrong neighbors. Annu Rev Ecol Evol Syst 40:1-20

10. Jactel H, Birgersson G, Andersson S, Schlyter F (2011) Non-host volatiles mediate associational resistance to the pine processionary moth. Oecologia 166:703-711

11. Zakir A, Sadek MM, Bengtsson M, Hansson BS, Witzgall P, Anderson P (2013) Herbivore-induced plant volatiles provide associational resistance against an ovipositing herbivore. J Ecol 101:410-417

12. Hooks CRR, Johnson MW (2003) Impact of agricultural diversification on the insect community of cruciferous crops. Crop Prot. 22:223-238

13. Newton AC, Begg GS, Swanston JS (2009) Deployment of diversity for enhanced crop function. Ann Appl Biol. 154:309-322

14. Andow DA (1991) Vegetational diversity and arthropod population response. Annu Rev Entomol 36:561-586

15. Song BZ, Wu HY, Kong Y, Zhang J, Du YL, Hu JH et al (2010) Effects of intercropping with aromatic plants on the diversity and structure of an arthropod community in a pear orchard. Biocontrol 55:741-751

16. Mauchline AL, Cook SM, Powell W, Osborne JL (2013) Effects of non-host plant odour on Meligethes aeneus during immigration to oilseed rape. Entomol Exp Appl 146:313-320

17. Finch S, Collier RH (2012) The influence of host and non-host companion plants on the behaviour of pest insects in field crops. Entomol Exp Appl 142:87-96

18. Yuan JS, Himanen SJ, Holopainen JK, Chen F, Stewart CN Jr (2009) Smelling global climate change: mitigation of function for plant volatile organic compounds. Trends Ecol Evol 24:323-331

19. Blande JD, Holopainen JK, Li T (2010) Air pollution impedes plant-to-plant communication by volatiles. Ecol Lett 13:1172-1181
20. Holopainen JK, Gershenzon J (2010) Multiple stress factors and the emis sion of plant VOCs. Trends Plant Sci 15:176-184

21. Heil M (2014) Herbivore-induced plant volatiles: targets, perception and unanswered questions. New Phytol 204:297-306

22. Loivamäki M, Mumm R, Dicke M, Schnitzler JP (2008) Isoprene interferes with the attraction of bodyguards by herbaceous plants. Proc Natl Acad Sci USA 105:17430-17435

23. Dicke M, Baldwin IT (2010) The evolutionary context for herbivoreinduced plant volatiles: beyond the 'cry for help.'Trends Plant Sci 15:167-175

24. Shelton AM, Badenes-Perez FR (2006) Concepts and applications of trap cropping in pest management. Annu Rev Entomol 51:285-308

25. Cook SM, Khan ZR, Pickett JA (2007) The use of push-pull strategies in integrated pest management. Annu Rev Entomol 52:375-400

26. Kaplan I (2012) Attracting carnivorous arthropods with plant volatiles: the future of biocontrol or playing with fire? Biol Control 60:77-89

27. Cook SM, Jönsson M, Skellern MP, Murray DA, Anderson P, Powell W (2007) Responses of Phradis parasitoids to volatiles of lavender, Lavandula angustifolia - a possible repellent for their host, Meligethes aeneus. BioControl 52:591-598

28. Glinwood R, Ninkovic V, Pettersson J (2011) Chemical interaction between undamaged plants - effects on herbivores and natura enemies. Phytochemistry 72:1683-1689

29. Wäschke N, Meiners T, Rostás M (2013) Foraging strategies of parasitoids in complex chemical environments. In: Wajnberg E, Colazza S (eds) Chemical ecology of insect parasitoids. Wiley, New York, pp 37-63

30. Vucetic A, Dahlin I, Petrovic-Obradovic O, Glinwood R, Webster B, Ninkovic V (2014) Volatile interaction between undamaged plants affects tritrophic interactions through changed plant volatile emission. Plant Signal Behav. 9:e29517

31. Braasch J, Kaplan I (2012) Over what distance are plant volatiles bioactive? Estimating the spatial dimensions of attraction in an arthropod assemblage. Entomol Exp Appl 145:115-123

32. Kesselmeier J, Staudt M (1999) Biogenic volatile organic compounds (VOC): an overview on emission, physiology and ecology. J Atmos Chem 33:23-88

33. Niinemets Ü, Loreto F, Reichstein M (2004) Physiological and physicochemical controls on foliar volatile organic compound emissions. Trends Plant Sci 9:180-186

34. Peñuelas J, Staudt M (2010) BVOCs and global change. Trends Plant Sci 15:133-144

35. Harrison SP, Morfopoulos C, Dani KGS, Prentice IC, Arneth A, Atwell BJ et al (2013) Volatile isoprenoid emissions from plastid to planet. New Phytol 197:49-57

36. Helmig D, Bocquet F, Pollmann J, Revermann T (2004) Analytical techniques for sesquiterpene emission rate studies in vegetation enclosure experiments. Atmos Environ 38:557-572

37. LiT, Blande JD (2015) Associational susceptibility in broccoli: mediated by plant volatiles, impeded by ozone. Glob Chang Biol 21:1993-2004

38. Furlong MJ, Wright DJ, Dosdall LM (2013) Diamondback moth ecology and management: Problems, progress, and prospects. Annu Rev Entomol 58:517-554

39. Talekar NS, Shelton AM (1993) Biology, ecology, and management of the diamondback moth. Annu Rev Entomol 38:275-301

40. Himanen SJ, Nerg AM, Nissinen A, Pinto DM, Stewart CN Jr, Poppy GM et al (2009) Effects of elevated carbon dioxide and ozone on volatile terpenoid emissions and multitrophic communication of transgenic insecticidal oilseed rape (Brassica napus L.). New Phytol 181:174-186

41. Jaenson T, Palsson K, Borg-Karlson A (2005) Evaluation of extracts and oils of tick-repellent plants from Sweden. Med Vet Entomol 19:345-352

42. Egigu MC, Ibrahim MA, Yahya A, Holopainen JK (2011) Cordeauxia edulis and Rhododendron tomentosum extracts disturb orientation and feeding behavior of Hylobius abietis and Phyllodecta laticollis. Entomol Exp Appl 138:162-174

43. Justus KA, Dosdall LM, Mitchell BK (2000) Oviposition by Plutella xylostella (Lepidptera: Plutellidae) and effects of phylloplane waxiness. J Econ Entomol 93:1152-1159

44. Eigenbrode SD, Espelie KE, Shelton AM (1991) Behavior of neonate diamondback moth larvae (Plutella xylostella L.) on leaves and on extracted leaf waxes of resistant and susceptible cabbages. J Chem Ecol 17:1691-1704 
45. Mauchline AL, Osborne JL, Martin AP, Poppy GM, Powell W (2005) The effects of non-host plant essential oil volatiles on the behaviour of the pollen beetle Meligethes aeneus. Entomol Exp Appl 114:181-188

46. Tang GB, Song BZ, Zhao LL, Sang XS, Wan HH, Zhang J et al (2013) Repellent and attractive effects of herbs on insects in pear orchards intercropped with aromatic plants. Agroforest Syst 87:273-285

47. Adati T, Susila W, Sumiartha K, Sudiarta P, Toriumi W, Kawazu K et al (2011) Effects of mixed cropping on population densities and parasitism rates of the diamondback moth, Plutella xylostella (Lepidoptera: Plutellidae). Appl Entomol Zool 46:247-253

48. Egigu MC, Ibrahim MA, Yahya A, Holopainen JK (2010) Yeheb (Cordeauxia edulis) extract deters feeding and oviposition of Plutella xylostella and attracts its natural enemy. Biocontrol 55:613-624

49. Gols R, Bukovinszky T, Hemerik L, Harvey JA, van Lenteren JC, Vet LEM (2005) Reduced foraging efficiency of a parasitoid under habitat complexity: implications for population stability and species coexistence. $J$ Anim Ecol 74:1059-1068

50. Randlkofer B, Obermaier E, Hilker M, Meiners T (2010) Vegetation complexity - the influence of plant species diversity and plant structures on plant chemical complexity and arthropods. Basic Appl Ecol 11:383-395

51. Bezemer TM, Harvey JA, Kamp AFD, Wagenaar R, Gols R, Kostenko O et al (2010) Behaviour of male and female parasitoids in the field: influence of patch size, host density, and habitat complexity. Ecol Entomol 35:341-351

52. Perfecto I, Vet LEM (2003) Effect of a nonhost plant on the location behavior of two parasitoids: the tritrophic system of Cotesia spp. (Hymenoptera: Braconidae), Pieris rapae (Lepidoptera: Pieridae), and Brassica oleraceae. Environ Entomol 32:163-174

53. Dicke M, de Boer JG, Höfte M, Rocha-Granados MC (2003) Mixed blends of herbivore-induced plant volatiles and foraging success of carnivorous arthropods. Oikos 101:38-48
54. Zhang QH, Schlyter F (2010) Inhibition of predator attraction to kairomones by non-host plant volatiles for herbivores: a bypass trophic signal. PLoS One 5:e11063

55. Bale JS, Masters GJ, Hodkinson ID, Awmack C, Bezemer TM, Brown VK et al (2002) Herbivory in global climate change research: direct effects of rising temperature on insect herbivores. Glob Chang Biol. 8:1-16

56. Sarfraz M, Dosdall LM, Keddie BA (2006) Diamondback moth-host plant interactions: Implications for pest management. Crop Prot. 25:625-639

57. Simoes P, Ott SR, Niven JE (2011) Associative olfactory learning in the desert locust, Schistocerca gregaria. J Exp Biol 214:2495-2503

58. Voigt W, Perner J, Davis AJ, Eggers T, Schumacher J, Bährmann R et a (2003) Trophic levels are differentially sensitive to climate. Ecology 84:2444-2453

59. Berggren Å, Björkman C, Bylund H, Ayres MP (2009) The distribution and abundance of animal populations in a climate of uncertainty. Oikos 118:1121-1126

60. Talekar NS, Yang JC (1991) Characteristic of parasitism of diamondback moth by two larval parasites. Entomophaga 36:95-104

61. Ibrahim MA, Mäenpää M, Hassinen V, Kontunen-Soppela S, Malec L, Rousi M et al (2010) Elevation of night-time temperature increases terpenoid emissions from Betula pendula and Populus tremula. J Exp Bot 61:1583-1595

62. Vuorinen T, Nerg A-M, Ibrahim MA, Reddy GVP, Holopainen JK (2004) Emission of Plutella xylostella-induced compounds from cabbages grown at elevated $\mathrm{CO}_{2}$ and orientation behavior of the natural enemies. Plant Physiol 135:1984-1992

\section{Submit your next manuscript to BioMed Central and take full advantage of:}

- Convenient online submission

- Thorough peer review

- No space constraints or color figure charges

- Immediate publication on acceptance

- Inclusion in PubMed, CAS, Scopus and Google Scholar

- Research which is freely available for redistribution

Submit your manuscript at 